\title{
Preliminary Assessment of Spatial Competition in the Market for E85
}

\section{Bentley Clinton \\ National Renewable Energy Laboratory \\ Department of Economics, University of Colorado Boulder}

February 2017

NREL/PR-6A20-67603 


\section{Overview}

- Motivation

- Assess retail pricing of E85

- Inform policy for future E85 expansion

- Provide benchmark prior to U.S. Department of Agriculture's Biofuel Infrastructure Partnership

- Question

- Does spatial competition in the market for E85 influence retail pricing behavior?

- Methods

- Econometric analysis using panel data set of station-level wholesale and retail fuel prices

- Conclusion

- Evidence of correlation between station density and E85 prices from publicly available data (e85prices.com) and purchased Minnesota data set (Oil Price Information Service)

- More station-level data may produce better-identified and more precise causal results 


\section{Background and Motivation}

- What are recent findings regarding E85 pricing?

- Retail E85 prices follow retail prices of regular gasoline.

- Margins for retail E85 are larger than margins for retail gasoline (Fuels Institute 2014).

- Why is this important?

- Higher E85 prices limit adoption for price-sensitive consumers.

- Adopters in some areas pay prices that are higher than they would be under cost-based pricing (RFA 2014).

- Where can we provide insight?

- Investigate one potential cause of deviation from cost-based pricing (local market power)

- No existing national studies of E85 competition

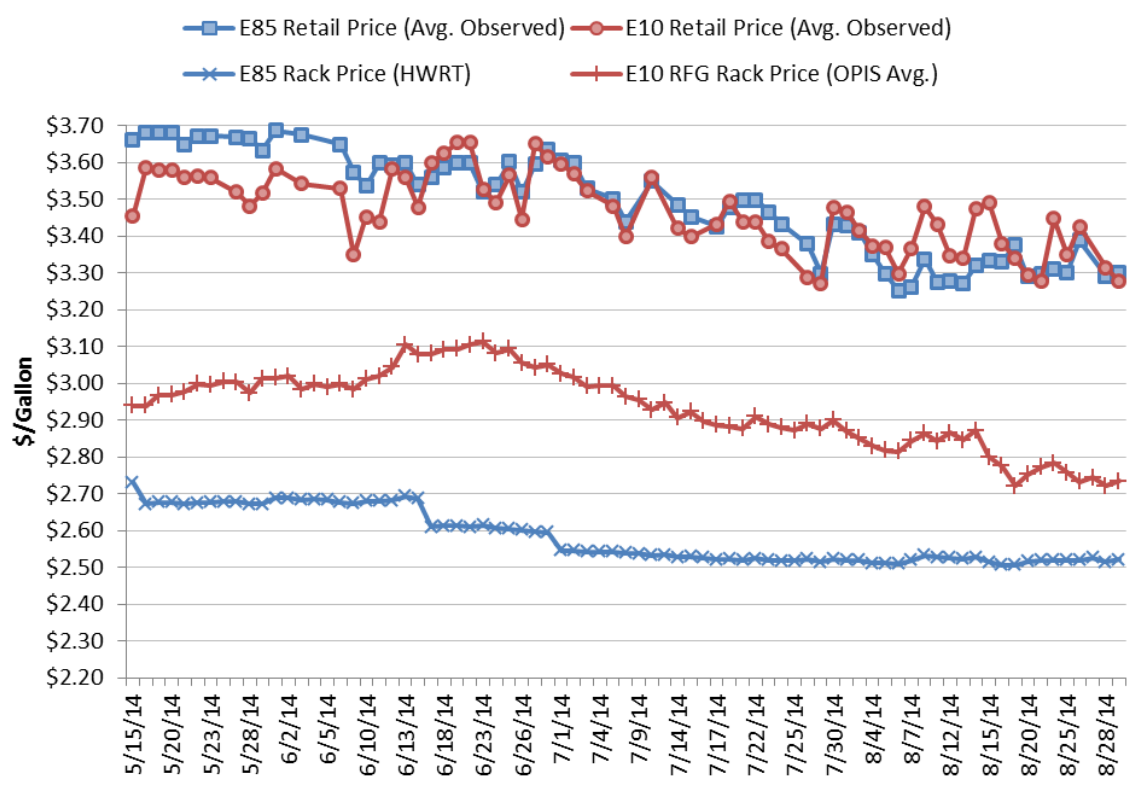

Figure 1. E85 and E10 pricing in St. Louis, 2014. Source: "Evidence of E85 Price Gouging?" Source: Renewable Fuels Association (2014); rack price data from OPIS, retail prices from study observations.

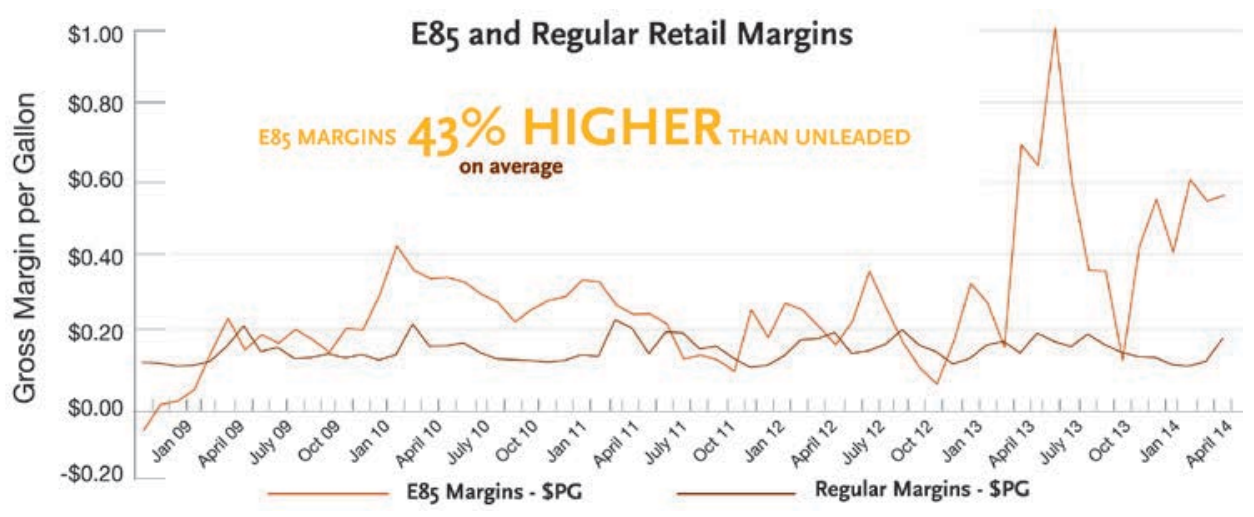

Figure 2. Retail margins for E85 and regular gasoline. Source: "E85: A Market Performance Analysis and Forecast," Fuels Institute (2014, November); data from NACS-CSX.00 


\section{Methodology}

- Data

- Publicly available data set for United States, 2007-2015

- Price observations reported by individual users based on retail price signage and fuel purchases

- Sources: Renewable Fuels Association (RFA), e85prices.com

- Proprietary data set for Minnesota, 2014

- Fuel prices recorded from credit card transactions and direct feeds from retailers

- Source: Oil Price Information Service (OPIS)

- Both data sets report concurrent retail prices for regular gasoline and E85 at individual stations

- Competition metrics

1. Number of competing E85 stations within a given radius

- Existing studies of this metric for retail gasoline: Lee (2007), Barron et al. (2004), Hastings et al. (2004)

- Evidence that lost retail gasoline sales are distributed to competing stations within a one-mile radius (Lee 2007)

2. Distance to nearest station that offers E85 


\section{Methodology}

- Empirical strategy

- Across-station variation (cross-sectional analysis)

- Compare pricing among stations given variation in spatial competition faced by each station

- Control for time-invariant, spatial variation (e.g., density of flexible-fuel vehicles, access to highway infrastructure, and local regulation) through spatial fixed effects

- Address national, time-varying effects (e.g., changes in E85 infrastructure costs, national trends in wholesale fuel cost, and E85 familiarity and adoption) with temporal fixed effects

- Within-station variation

- Track price variation for a single station when number of nearby E85 competitors changes

- Replace spatial fixed effects with station-level fixed effects to control for station-level, timeinvariant effects (e.g., brand, location, and amenities)

- All models control for same-day, same-station retail gasoline price.

- Estimates of local market power effects are computed in terms of change in price (\$/gal) and percent change in price. 


\section{National Analysis: Data-Price Series}

- Compiled national price series

- Publicly available, user-reported pricing data from e85prices.com

- Prices reported between January 2007 and August 2015

Figure 3. Map of E85 Stations in National Data Set

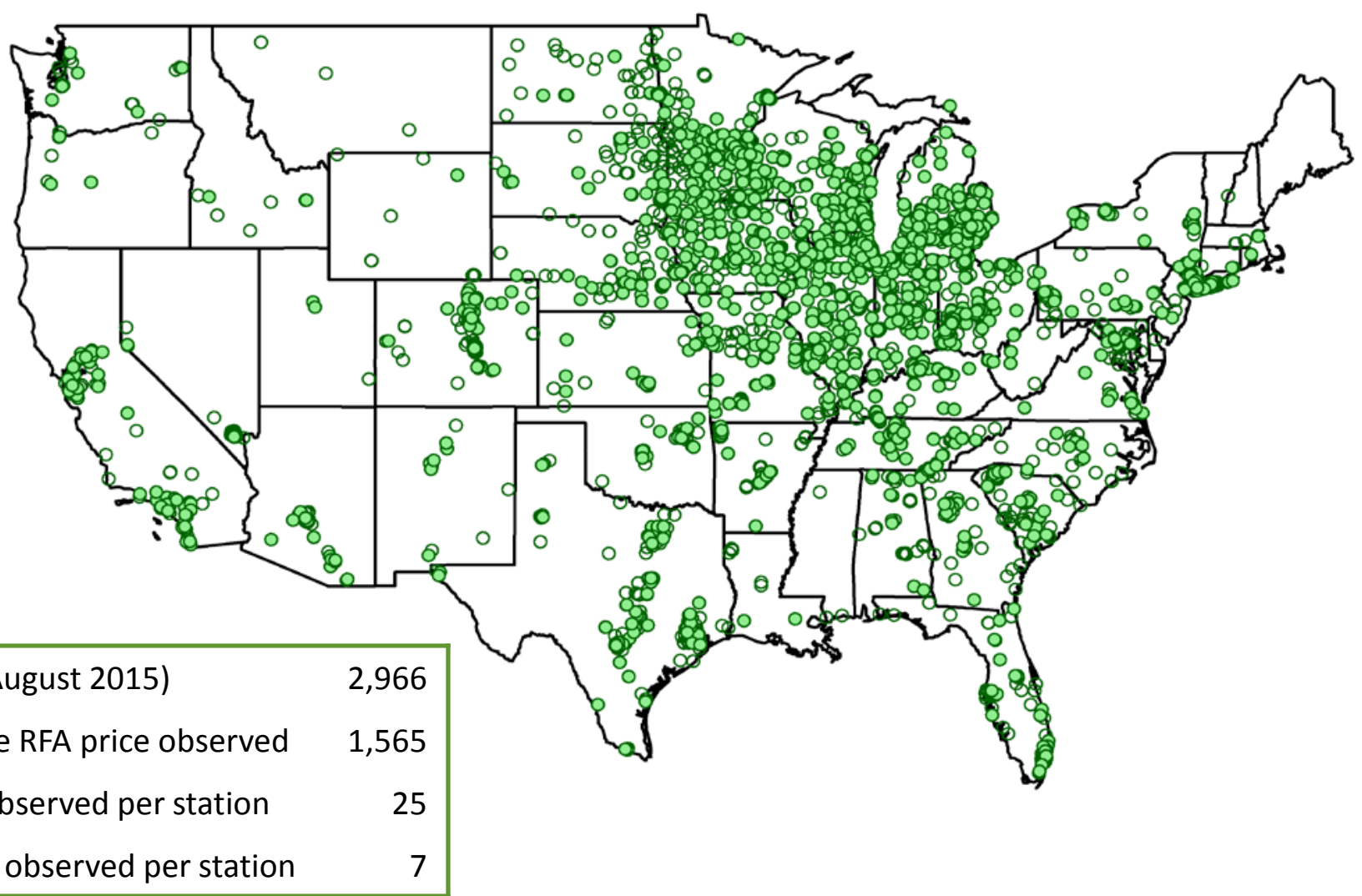

Notes: Circles represent E85 stations. Circles with light green fill represent stations with at least one price observation. Sources: AFDC, E85Prices.com, Clean Cities. 


\section{National Analysis: Data-Price Spreads}

Figure 4. Price Spread in \$/gallon

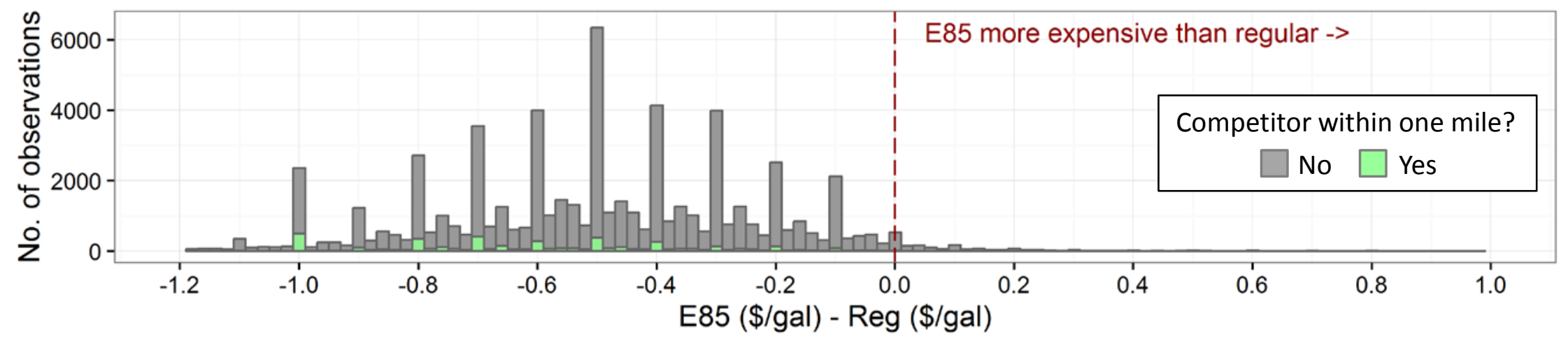

Figure 5. Price Spread in $\$ /$ GGE

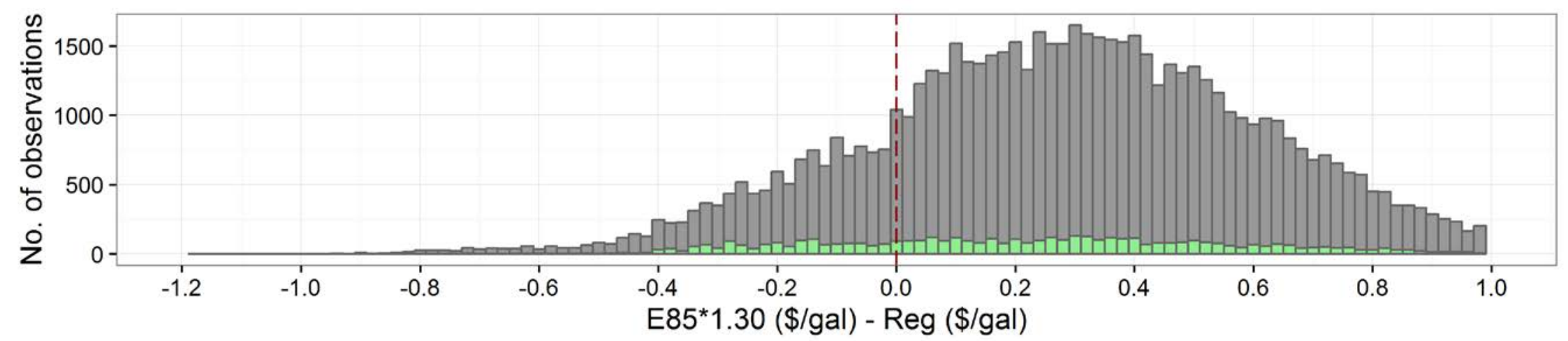

\begin{tabular}{|c|c|c|c|c|}
\hline \multirow{2}{*}{ Spread Units } & \multirow{2}{*}{$\begin{array}{c}\text { Competitor within } \\
\text { One Mile? }\end{array}$} & Number of Price & \multicolumn{2}{|c|}{ Percent of Price Observations } \\
\cline { 3 - 5 } & Observations & E85 Less Expensive than Regular & E85 More Expensive than Regular \\
\hline \multirow{2}{*}{ \$/gal } & No & 33,253 & 97.8 & 2.2 \\
& Yes & 5,116 & 98.1 & 1.9 \\
\multirow{2}{*}{ \$/GGE } & No & 33,253 & 22.4 & 77.6 \\
& Yes & 5,116 & 28.2 & 71.8 \\
\hline
\end{tabular}

Note: Gasoline gallon equivalent (GGE) assumes 70 percent ethanol blend. [E85 \$/GGE]=[E85 \$/gal]*1.30. Source: Clean Cities 2015. 


\section{National Analysis: Results-Station Density}

Figure 6. Station Density Pricing Impacts

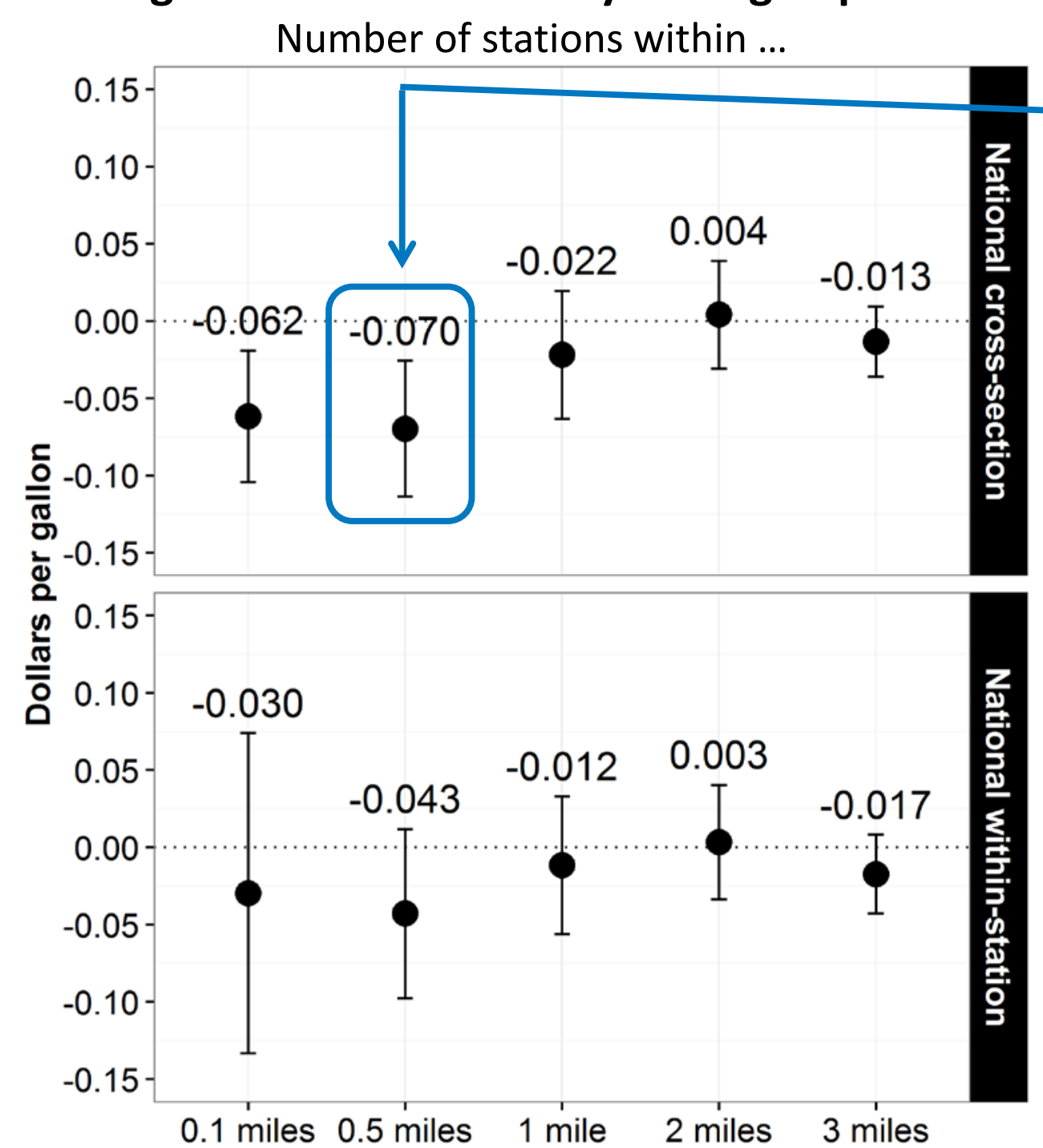

Interpretation: One more station offering E85 within 0.5 miles is associated with a \$0.07 lower E85 price per gallon, all else being equal. Confidence intervals indicate estimates range from approximately $-\$ 0.11$ to $-\$ 0.03$.

- Cross-section results

- Spatial competition associated with lower E85 pricing within 0.5 miles

- Within-station results

- Point estimates suggest possible inverse relationship between E85 prices and spatial density

- Coefficient estimates for variables of interest lack statistical significance

- Imprecise estimates likely result from limited number of observable price and station density changes (e.g., five identifying stations at 0.1 miles for within-station analysis) 


\section{National Analysis: Results-Competitor Proximity}

\section{Figure 8. Competitor Proximity Pricing Impacts}

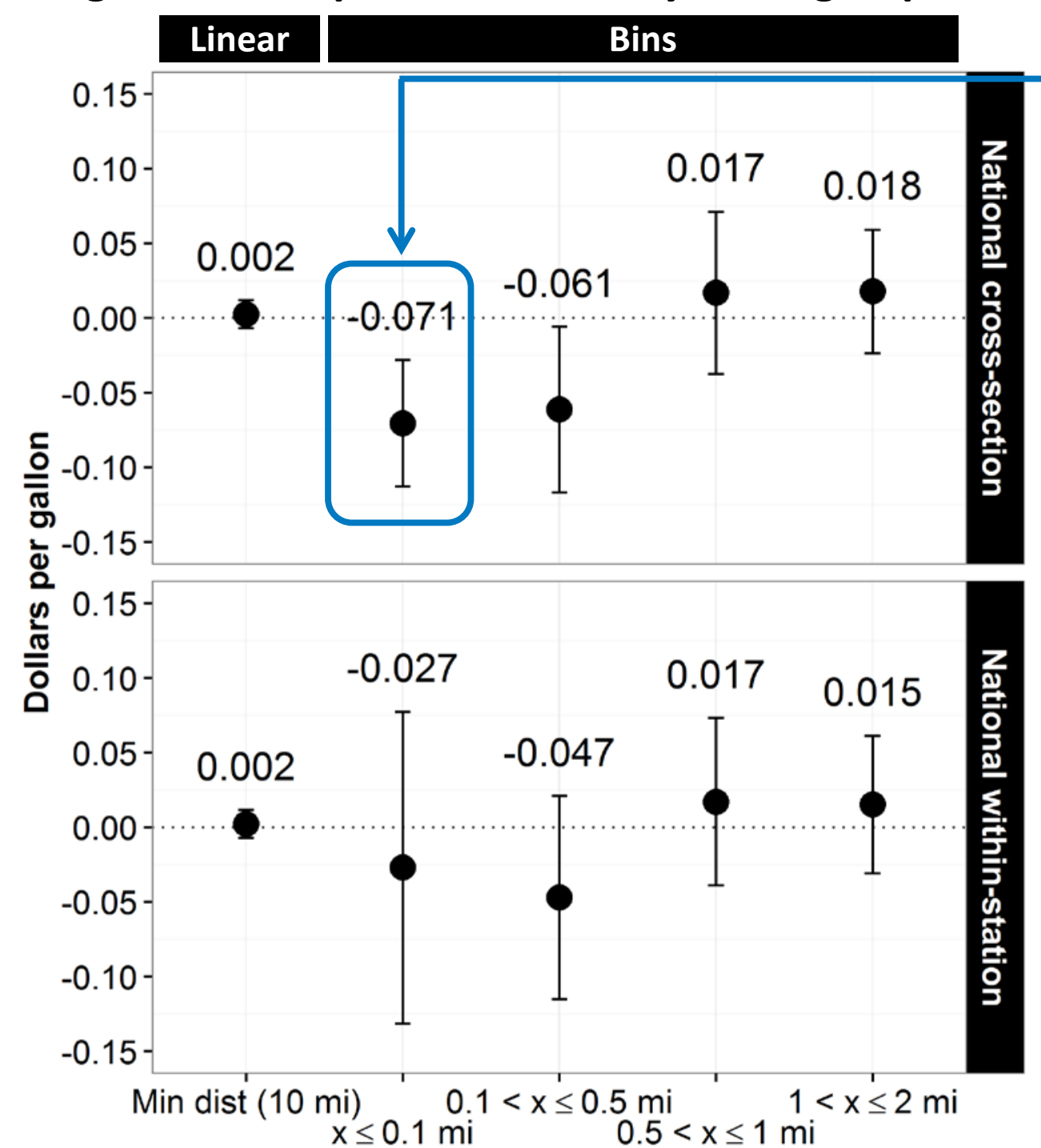

Interpretation: A station whose nearest competitor is within 0.1 miles will price E85 approximately $\$ 0.07$ per gallon lower than an otherwise identical station whose nearest competitor is more than two miles away.

- Linear minimum distance metric

- Neither cross-section nor withinstation specification indicates a statistically significant relationship between nearest competitor distance and E85 pricing

- Result possibly due to non-linear relationship between competitor proximity and E85 price

- Binned minimum distance metric

- Cross-sectional analysis reveals a statistically significant relationship within 0.5 miles

- Within-station results lack precision, but point estimates display a pattern similar to the cross-sectional result

Notes: Dots and labels indicate point estimate values. Error bars represent $95 \%$ confidence intervals. The omitted bin is nearest competitor more than two miles away. 


\section{National Analysis: Results-Competitor Proximity}

\section{Figure 9. Competitor Proximity Pricing Impacts}

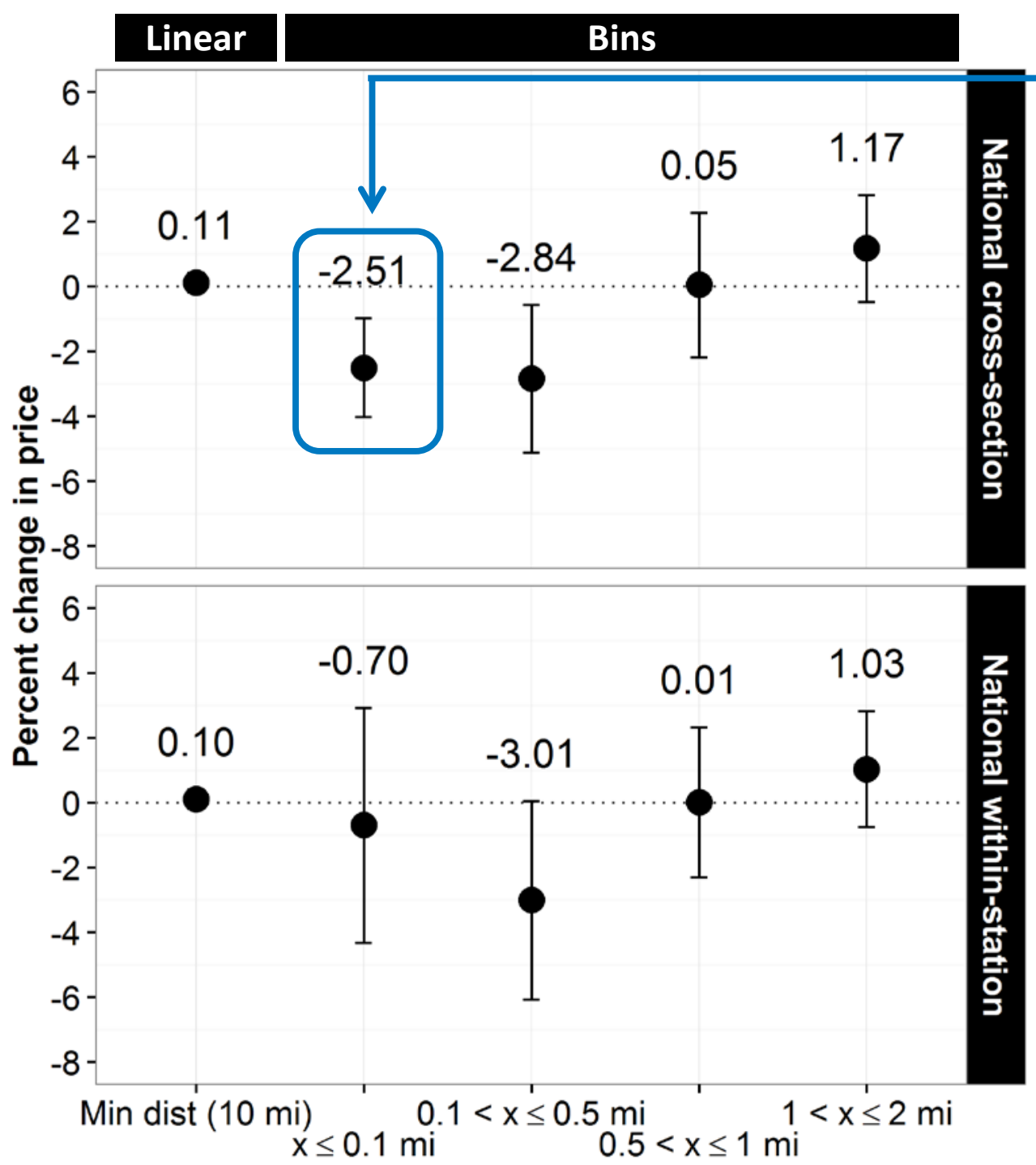

Interpretation: A station whose nearest competitor is within 0.1 miles is associated with a 2.9 percent lower E85 price per gallon than an otherwise identical station whose nearest competitor is more than two miles away.

- Impacts in percent price change

- Point estimates of competition effect are qualitatively similar to price changes

- Cross-sectional analysis of competitive effects within 0.5 miles maintains significance at the 95 percent level 


\section{Alternative Data Set: Minnesota}

- Oil Price Information Service (OPIS) proprietary retail price data

- Station-level prices and station attributes for all Minnesota stations in 2014

- Daily prices for regular gasoline and E85 purchases included in data set

- Minnesota identified as best candidate for data purchase based on conversations with OPIS personnel and analysis of E85 station entry from AFDC data

- Cross-referenced OPIS price reports with AFDC station identification data and RFA user-reported prices from e85prices.com

- Where possible, supplemented data with RFA observations 


\section{Minnesota Analysis: Data-E85 Stations}

Table 1. Counts and Average Prices for Minnesota E85 Stations, 2014

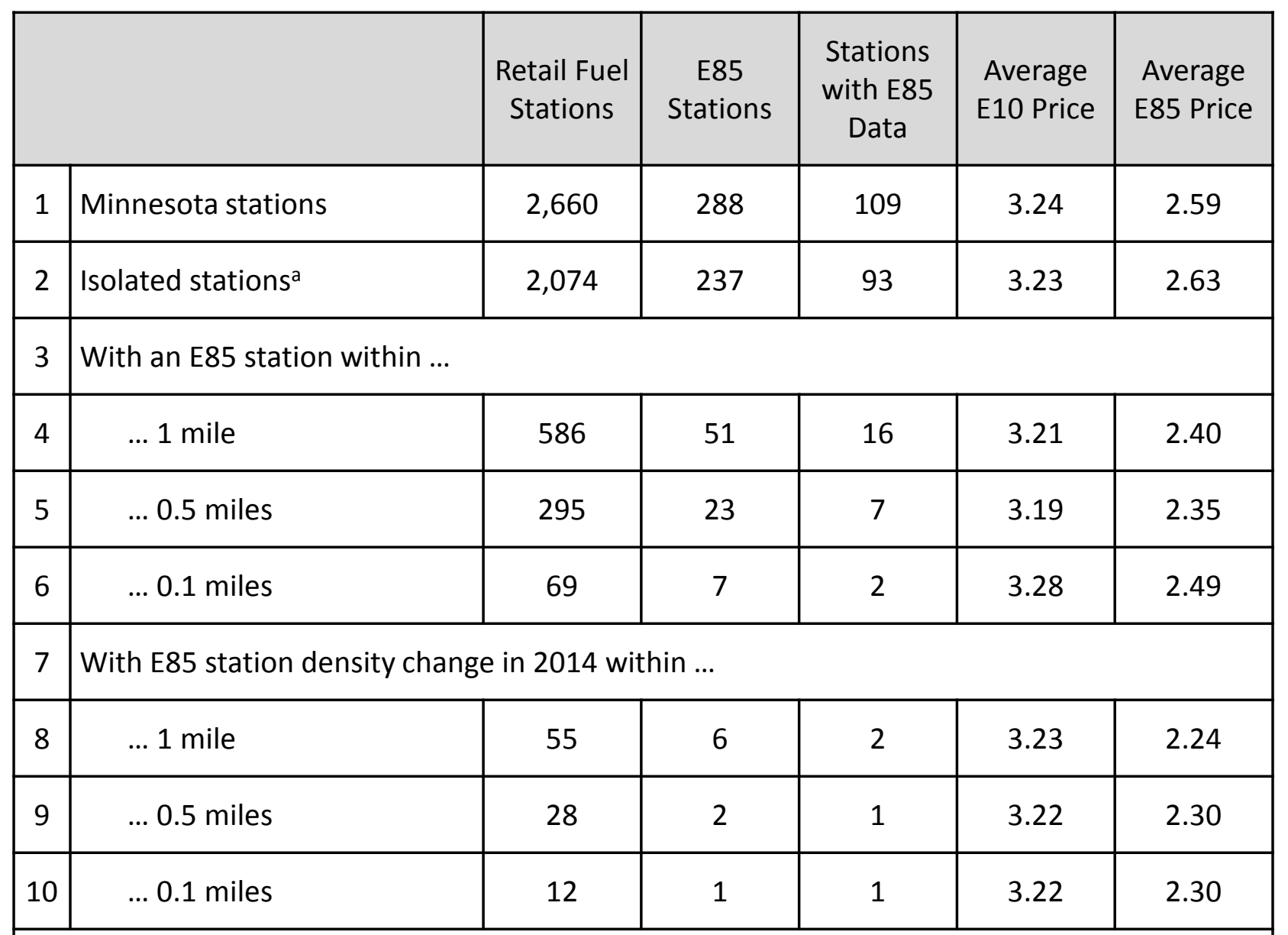

Retail fuel prices in dollars per gallon. Price data are from OPIS and in the absence of OPIS price observations are supplemented with RFA user-reported data. Minnesota stations exclude unidentifiable stations and 12 restricted access stations. AFDC data identify 18 stations that enter the E85 market in Minnesota in 2014.

a Row 2 ("isolated stations") reports data for E85 stations without another E85 station within one mile.

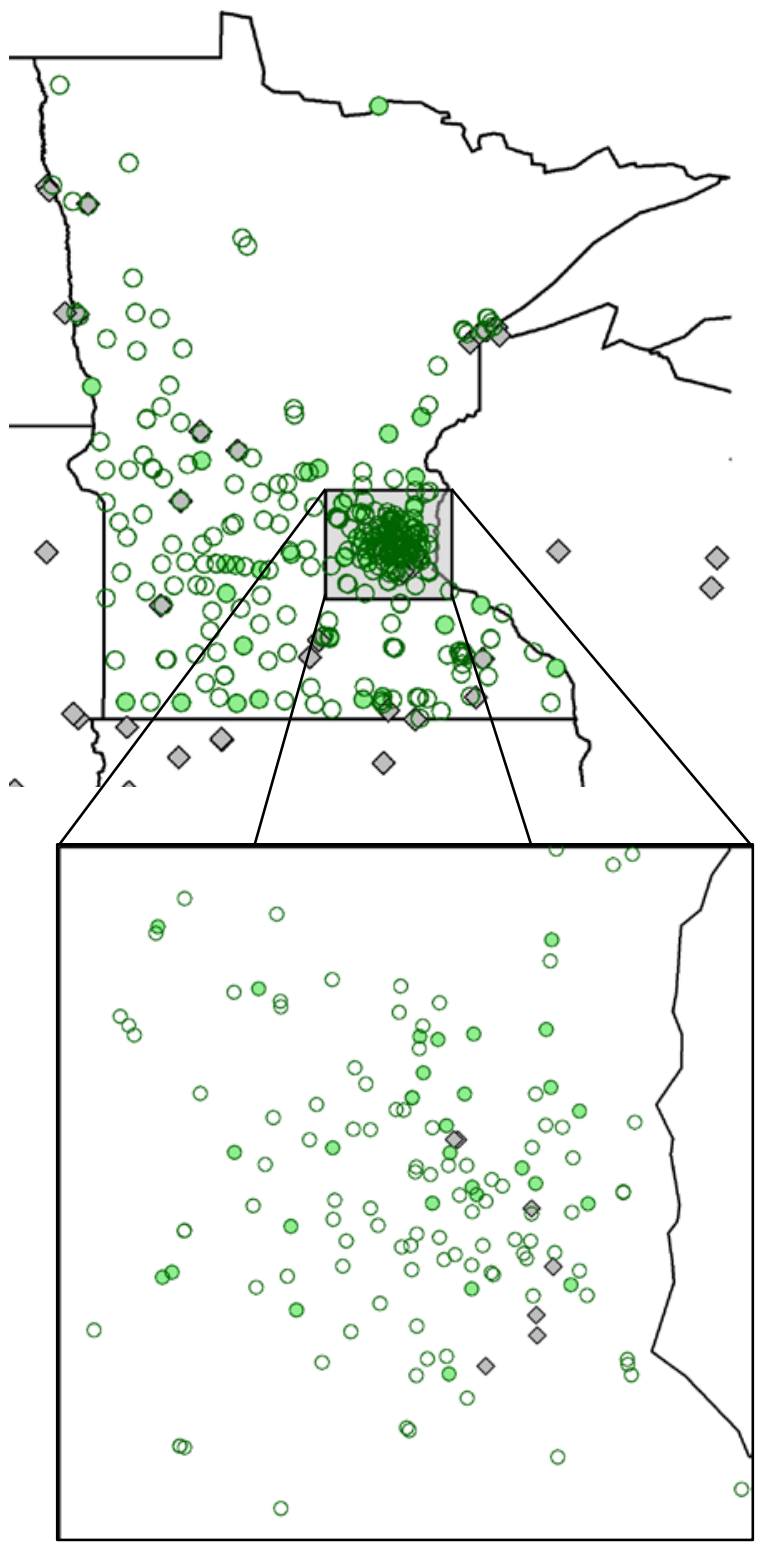




\section{Minnesota Analysis: Data-Price Spreads}

Figure 10. Price Spread in \$/gallon

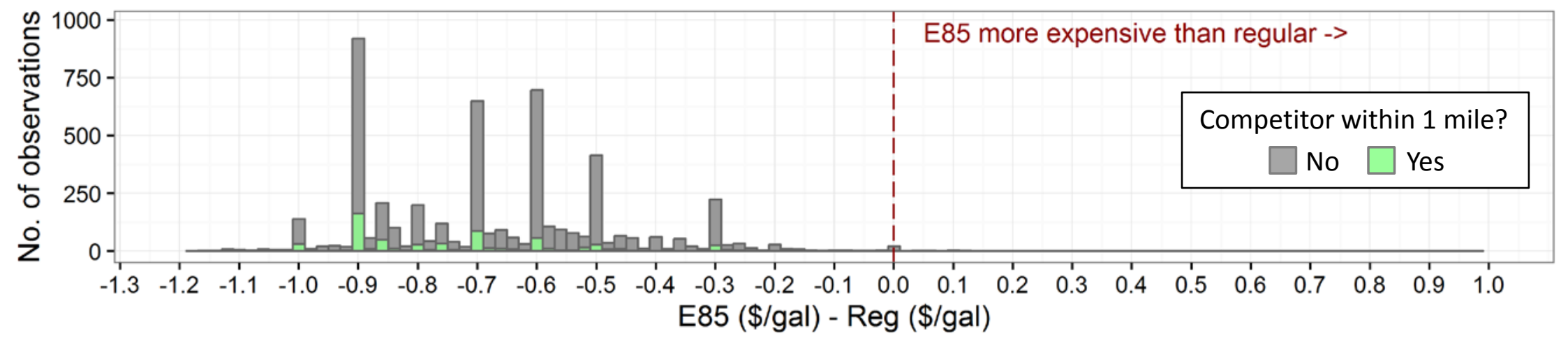

Figure 11. Price Spread in $\$ / G G E$

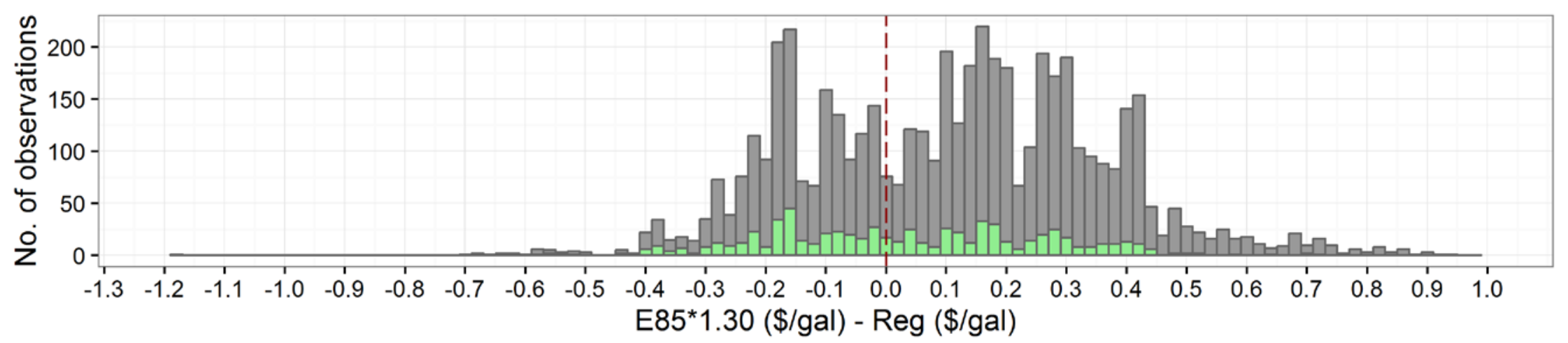

\begin{tabular}{|c|c|c|c|c|}
\hline \multirow{2}{*}{ Spread Units } & \multirow{2}{*}{$\begin{array}{c}\text { Competitor within } \\
\text { One Mile? }\end{array}$} & \multirow{2}{*}{$\begin{array}{c}\text { Number of Price } \\
\text { Observations }\end{array}$} & \multicolumn{2}{|c|}{ Percent of Price Observations } \\
\cline { 3 - 5 } & No & 4,354 & 99.7 & 0.3 \\
\multirow{2}{*}{ \$/gal } & Yes & 708 & 99.8 & 0.2 \\
& No & 4,354 & 33.7 & 66.3 \\
\multirow{2}{*}{ \$/GGE } & Yes & 708 & 48.4 & 51.6 \\
\hline
\end{tabular}




\section{Minnesota Analysis: Results-Station Density}

\section{Figure 15. Station Density Pricing Impacts}

Number of stations within ...

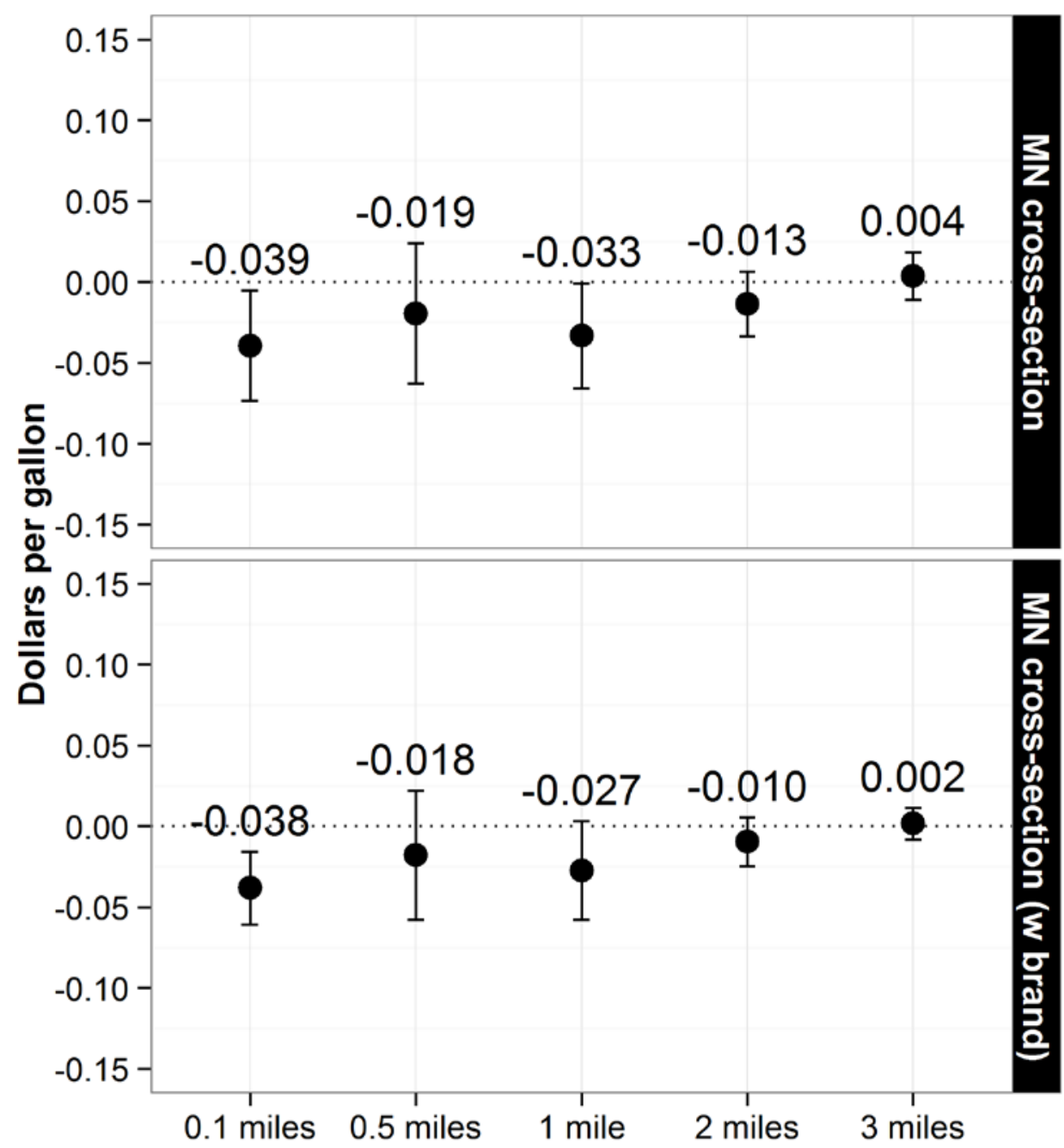

- Cross-section results

- Spatial competition associated with lower E85 pricing within one mile

- Insufficient identifying variation in data set for within-station analysis

- Two stations with variation within one mile, one station with variation within 0.1 miles.

- Refinement with station brand controls produces similar point estimates and decreases variance 


\section{Minnesota Analysis: Results-Competitor Proximity}

\section{Figure 17. Competitor Proximity Pricing Impacts}

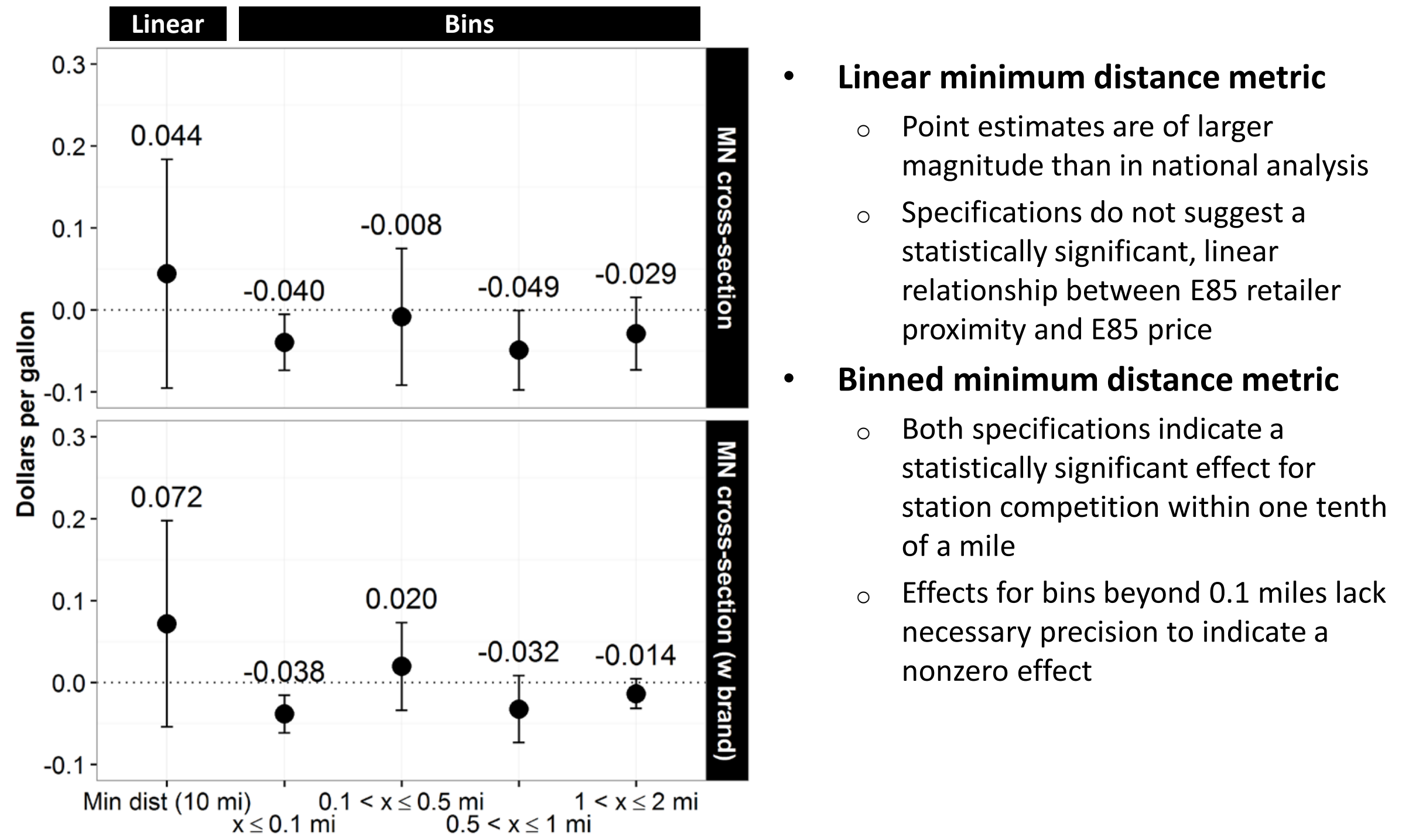

Notes: Dots and labels indicate point estimate values. Error bars represent $95 \%$ confidence intervals. The omitted bin is nearest competitor more than two miles away. 


\section{Minnesota Analysis: Results-Competitor Proximity}

\section{Figure 18. Competitor Proximity Pricing Impacts}

\section{Linear}

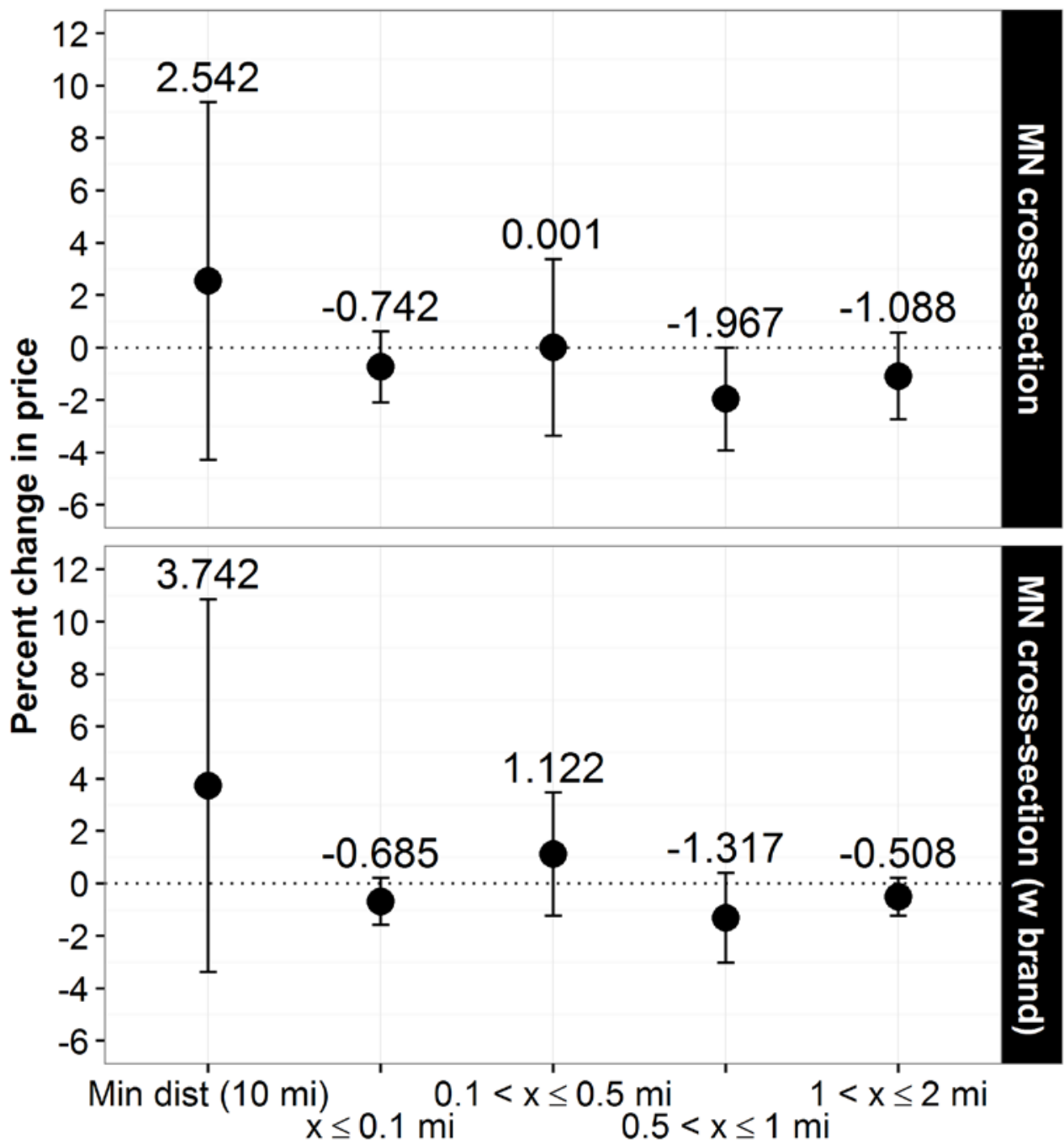

- Impacts in percent price change

- Point estimates of competition effect are again qualitatively similar to price changes

- No estimates demonstrate statistical significance at the 95 percent level 


\section{Summary, Discussion, and Conclusions}

- Conclusions

- Descriptive analysis

- Correlation between E10 and E85 retail pricing

- Evidence that E85 price differences are possibly due to local market power

- Econometric analysis

- Inverse relationship between retail E85 prices and station density

- Indications of nonlinear effect of competitor proximity on E85 prices

- Data availability-a primary concern for future analysis of E85 pricing behavior

- Current sources (RFA, OPIS) lack comprehensive retail price coverage for E85

- Improved data may produce more precise and better-identified results

- Questions or comments 


\section{About the Project}

This analysis was conducted by Bentley Clinton as part of the Research Participant Program at the National Renewable Energy Laboratory while pursuing a Ph.D. degree in the Department of Economics, University of Colorado Boulder.

Contact: bentley.clinton@colorado.edu

The following colleagues and reviewers are acknowledged for their helpful comments:

- U.S. Department of Energy

- NREL colleagues Michael Elchinger, Caley Johnson, Kristi Moriarty, Emily Newes, Daniel Steinberg, and Laura Vimmerstedt

NREL contacts: laura.vimmerstedt@nrel.gov or emily.newes@nrel.gov

- Daniel Kaffine, Associate Professor, University of Colorado-Boulder

- Participants in related presentations at the University of Colorado-Boulder

- Participants at the 2016 annual meeting of the Northeast Agricultural and Resource Economics Association

For additional detail, please see the related technical report (Clinton 2017). 


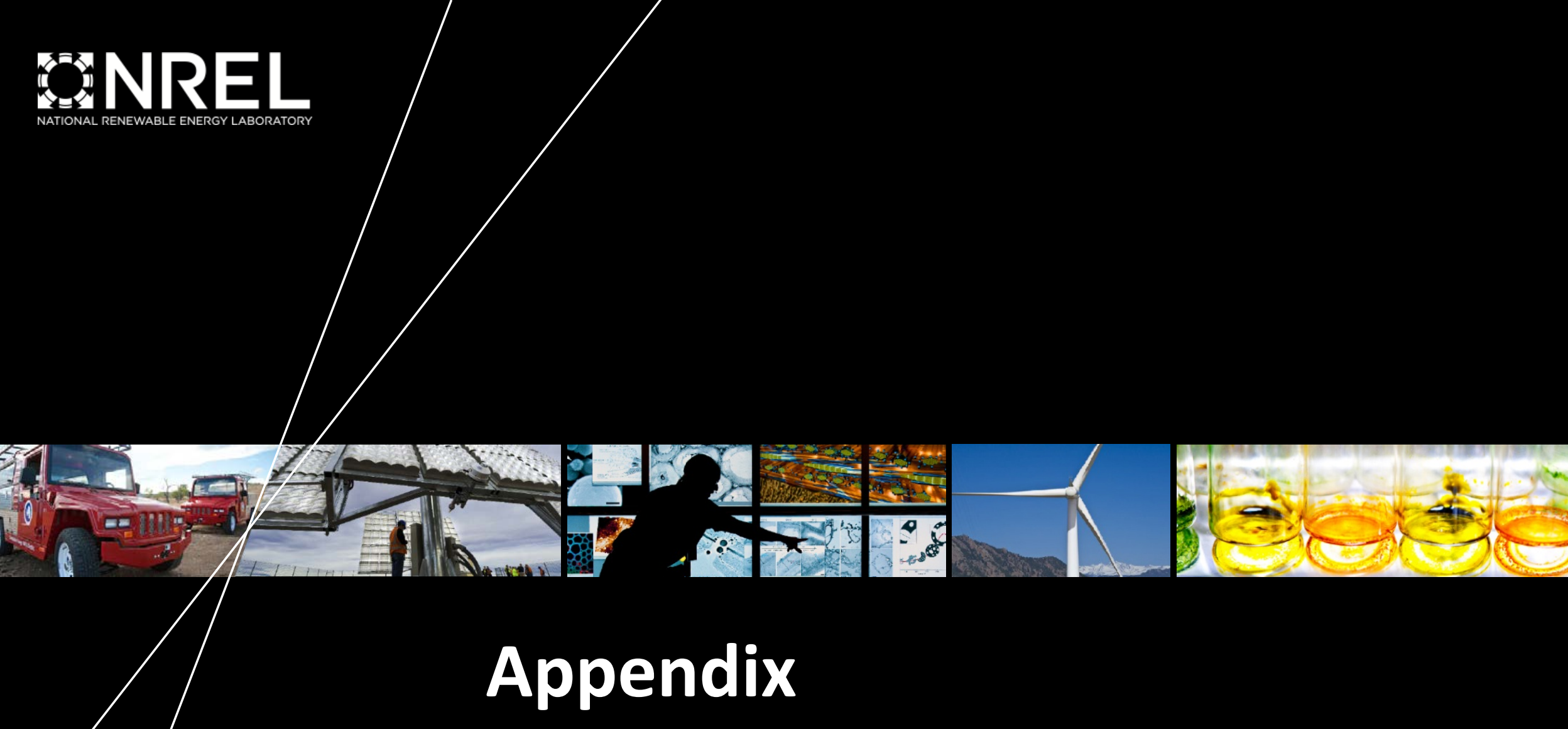


Figure 11. Price Spread in \$/GGE

[Repeated from Slide 14]

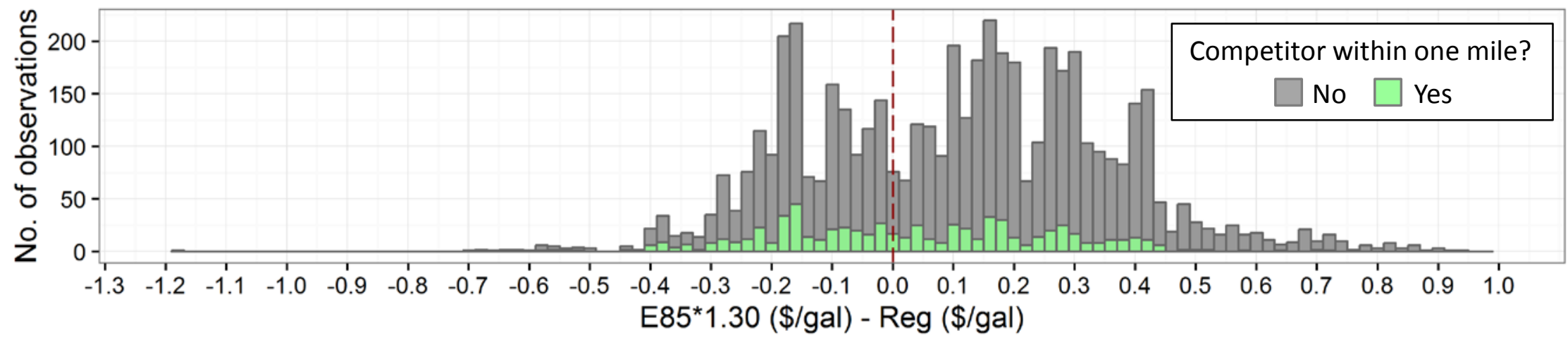

Figure 19. Price Spread in \$/GGE with Seasonal Adjustment

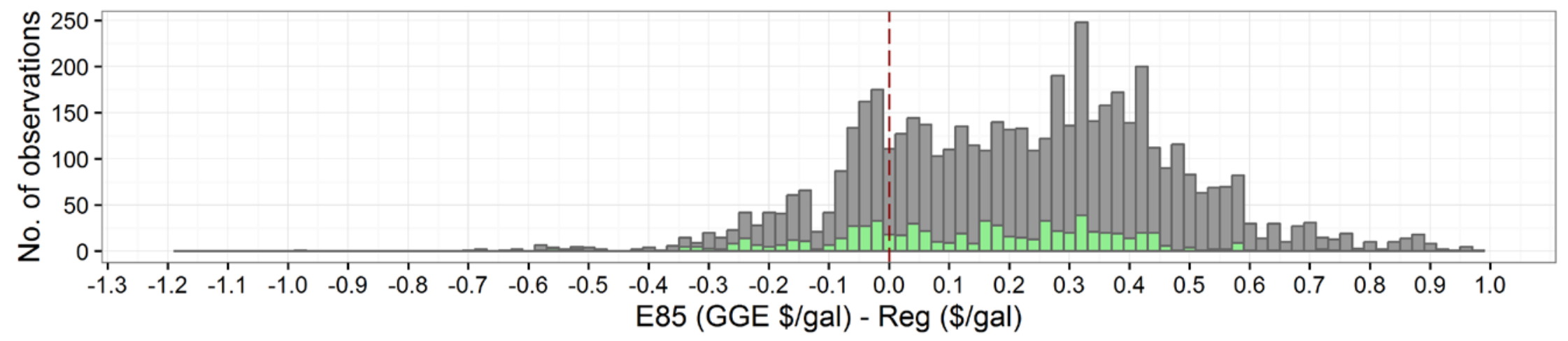

\begin{tabular}{|c|c|c|c|}
\hline \multirow{2}{*}{ Spread Units } & \multirow{2}{*}{$\begin{array}{c}\text { Competitor } \\
\text { within One Mile? }\end{array}$} & E85 Less Expensive than Regular & E85 More Expensive than Regular \\
\cline { 3 - 4 } & No & 99.7 & 0.3 \\
\multirow{2}{*}{ \$/gal (Figure 10) } & Yes & 99.8 & 0.2 \\
\hline \multirow{2}{*}{ \$/GGE (Figure 11) } & No & 33.7 & 66.3 \\
& Yes & 48.4 & 51.6 \\
\hline \$/GGE with seasonal & No & 22.0 & 78.0 \\
adjustment (Figure 19) & Yes & 33.1 & 66.9 \\
\hline
\end{tabular}

Note: Seasonal adjustment assumes retail fuel contains minimum amount of ethanol based on volatility classes for E85. “Handbook for Handling, Storing, and Dispensing E85 and Other Ethanol-Gasoline Blends," U.S. Department of Energy, February 2016. 


\section{References}

Barron, John M., Beck A. Taylor, and John R. Umbeck. 2004. "Number of Sellers, Average Prices, and Price Dispersion." International Journal of Industrial Organization 22(8):1041-1066.

Clinton, Bentley. 2016. Preliminary Assessment of Spatial Competition in the Market for E85. Golden, CO: National Renewable Energy Laboratory. NREL/TP-6A20-66943.

http://www.nrel.gov/docs/fy17osti/66943.pdf.

Fuels Institute. 2014. E85: A Market Performance Analysis and Forecast.

Hastings, Justine S. 2004. "Vertical Relationships and Competition in Retail Gasoline Markets: Empirical Evidence from Contract Changes in Southern California." American Economic Review 94(1):317-328.

Lee, Sang-Yeob. 2007. "Spatial Competition in the Retail Gasoline Market: An Equilibrium Approach Using SAR Models." The Ohio State University. Working paper.

RFA (Renewable Fuels Association). 2014. Evidence of E85 Price Gouging? A Case Study of the St. Louis E85 Market. Renewable Fuels Association. http://www.ethanolrfa.org/wpcontent/uploads/2015/09/Evidence-of-E85-Price-Gouging.pdf.

Additional references and a detailed literature review are included in the forthcoming technical report (Clinton 2017) 